\title{
Evaluation on the Impact of a Soccer Training Program on the Moral Development of Teenage Participants 社區中心所舉辦之足球活動對青少年品德發展的影響
}

\author{
Eric C.K. TSANG \\ Department of Creative Arts and Physical Education (PE Division) \\ The Hong Kong Institute of Education, HONG KONG \\ 曾卓權 \\ 香港教育學院體藝學系(體育學部)
}

\begin{abstract}
This study examined the impact of a soccer training program organized by a district social service group on the moral development of 35 teenage participants. Participants took part in the interview which aimed at finding out their attitude towards the program by understanding their intention of participation, perceived benefits, attitude towards winning and losing, and the reason of adherence. Assessment from parents and teachers were made by using the Strength and Difficulties Questionnaire (SDQ; Goodmam, 1997). Results suggested that the program participants adopted a positive attitude towards participation by demonstrating strong team cohesion. Feedback from parents and teachers also consolidated that program participants generally demonstrated a normal behavior towards society. Base on findings from the study, recommendations were made for the launching of similar program and suggested directions for further studies.
\end{abstract}

\section{摘 要}

本文根據某社區中心所舉辦之足球訓練活動，探討其對青少年品德發展的影響。研究方法包括與參加者面談、及利用問 卷形式由参加者老師及家長評核其品德發展及對社會之認同。研究結果, 肯定該足球訓練活動, 對青少年品格發展有正面影響。 本文根據研究結果, 對推行類似活動提出建議, 及提出將來研究的方向。

\section{Introduction}

With an increase in adolescent problem behaviors and decaying family structure (increases in unsupervised child at home alone), the future of today's youth has been a growing concern in our society. According to the report from the Security Bureau, HKSAR, there were 4,510 juveniles (age between 10 to 15) and 4,974 young persons (age between 16 to 20) arrested for crime in the year 2006 (Security Bureau, 2006). Cheng, Lo, and Wong in a study (2004) through self-report investigating deviant behaviors found that negative behaviors of drinking alcohol (4.1\%), smoking (8.6\%), verbally attacking teachers (2.09\%), taking drugs (1.15\%), verbally attacking parents (11.4\%) and physical destruction and bullying (5.5\%) frequently occurred among the sample of 1,432 secondary school children in Hong Kong.

Youth sport programs have been extensively used to foster a positive social development for youth. Sport, which provides a vehicle for learning to cooperate with teammates, negotiate and give solutions to moral conflicts, develop self control, display courage, and learn virtues such as fairness, team loyalty, persistence and teamwork (Shields \& Bredemeier, 1995), has always been considered as a "character builder". 
A youth social service group in Tze Wan Shan, Hong Kong, has launched a soccer training program started in 2004. The program aims at providing some meaningful organized physical activities for young people that can develop their physical capacities, and more importantly, foster their moral development. The program has been operating for almost four years and this study was conducted to investigate the effectiveness of the program with respect to the behavioral changes of participants after joining the program. Data were collected from the participants themselves as well as their parents and school teachers.

\section{Positive Youth Experiences through Sport}

Numerous studies have been conducted to investigate the effect of sport involvement on youth development. Studies (Bar-Or, 1983; Cote \& Hay, 2002) reported positive findings that it facilitated the physical growth of children through the development of their cardiovascular fitness, improvement of muscular strength and endurance, and able to control their weight. Aaron and his colleagues (1995) also found that those adolescents involved in regular physical activities were less likely to smoke.

Positive findings were reported that sport and physical activity could foster psychological and emotional development. Gilman (2001) found that those actively participated in extracurricular activities reported higher life satisfaction among youth.

Another study (Fraser-Thomas \& Cote, 2005) found that those involved in organized sport activities experienced significantly more happiness in their daily living.

Studies also indicated that social development could be achieved through sport participation. In testing the Sport Commitment Model, Scanlan and his associates (1993) concluded that youth demonstrated discipline and commitment in sport which could carry over into other domains of life. Larson (2000) also proposed that participation in structured activities such as sport could provide the "initiative" that was crucial to youths' positive social development.

Numerous studies (Dwyer et al., 2001; Eccles \& Barber, 1999) have found the positive relationship between students' involvement in physical activities and their academic performance. This positive relationship extended to other performances in schools such as attendance, dedication to school work and other educational aspirations. Similar findings were concluded in a local study in Hong Kong (Lindner, 1999).

\section{Negative Youth Experiences through Sport}

Negative influences on physical development were also reported in some studies mostly related with sport injuries (Hollander et al., 1995) and eating disorder (Anshel, 2004). The competitive nature of sport activities also hampered the emotional and psychological development of youth. The study by Wankel and Kreisel (1985) showed that the excessive pressure to win and pressure from other team members led youth to experience low selfconfidence and low self-esteem. Negative social outcomes were witnessed by the increasing acts of violence and aggressive behavior in youth sport settings which, in many occasions, considered acceptable and legitimate within the sport environment (Gardner \& Janelle, 2002).

\section{The Soccer Training Program}

The soccer training program was organized by a social service group in Tze Wan Shan which aimed at providing an opportunity for those junior soccer players a chance to take part in competitions even they were not qualified for higher level regular league competitions. Through these activities, participants were expected to develop their own ethnical value and internalize a set of positive values towards society. The whole program was made up of four elements: skill training, competitions, discussion sessions and individual counseling. A three-hour skill training session was held every Saturday morning in their district soccer pitch. Trainers were hired to conduct the session. Besides providing technical support, social workers were also present to maintain interaction with participants and, hence, players were more alert on their behavioral expression and exert more personal control.

Regular matches or friendly matches were organized about once every month. During the game, social workers would observe the behavior of the participants and evaluate on their ability to adapt under stressful situations. Debriefing sessions would be held after each match and discussions would be centered on their skill and tactical performance, as well as on appropriate or inappropriate behaviors demonstrated. 
Regular discussion sessions were held once every month. In the one and a half hours discussion session, social workers would refer to some incidents or anecdotes about their soccer team and participants were encouraged to share their views. Through the sharing session, it was hoped that participants could be aware of different points of view, how to appreciate different cognitions of peers, and the way to communicate with other people.

Individual counseling would be made when personal problems or needs were identified which aimed at giving support to individuals in adapting to the society and getting along with other people. Activities ranged from team building activities, referee training courses to learning of appropriate etiquette in soccer activities.

\section{Method}

\section{Participants}

Two groups of participants who joined the soccer training program offered by the Social Service Group were invited to take part in the study. The first group $(\mathrm{n} 1=15)$ joined the program for about 4 years and the second group $(\mathrm{n} 2=20)$ joined the program for about 2 years. Most of them were secondary 5 students $(n=23)$, age range from 14 to 18 (mean $=15.97$ years). They came from nine different schools in the Wong Tai Sin District.

Upon the consent of the participants and their respective school principals, a teacher of each participant was contacted and invited to take part in this study by evaluating the participant's behavioral performance by using a set of questionnaires. Contacts were made through the PE master/mistress and they would nominate a teacher who had a better understanding of the student to complete the questionnaires. Normally, either the PE teachers or the class teachers of respective participants would be nominated.

After seeking consent from program participants, the parent of each program participant was also contacted to take part in this study by giving comments on their children's behavioral performance at home. In this study, 20 parents were successfully contacted.

\section{Instrument}

In this study, in-depth interviews with program participants were used. During the interviews, descriptive data in the participants' own words were gathered in order to develop insights on how they perceived the soccer training program. In order to secure the vividness of their recollection, participants were asked to quote practical examples. The interview was unstructured but focused on particular topics investigating their intention of participation, their perceived benefits of participation, their attitude towards winning and losing, and their reason of adherence to the program. The general interview guide approach (Patton, 1980) was used which involved outlying a set of issues concerning the various aspects of investigation. The issues in the outline were not taken in any particular order or wording and simply served as a basic checklist during the interview in order to make sure that all relevant topics were covered.

Teachers of respective schools were asked to complete a translated Chinese version of Strengths and Difficulties Questionnaire (SDQ, Goodman, 1997). They were asked to rate their students' behavior over the last 6 months.

The parent of the program participants were contacted through telephone calls. They were asked to rate their children's behavioral changes over the last six months. Questions were based on the Strengths and Difficulties Questionnaire (SDQ, Goodman, 1997).

The Strengths and Difficulties Questionnaire (SDQ) was developed by Goodman (1997) as a behavioral screening tool used by parents and teachers. The 25 SDQ items were reduced into 5 scales of 5 items each; they were: hyperactivity scale, emotional symptoms scale, conduct problems scale, peer problems scale, and prosocial scale. Total difficulties score was obtained by summing up all the scores except the "prosocial score" which was conceptually different from the presence of psychological difficulties. The original version was in English and was translated by the investigator into Chinese. Both the original English version and the translated Chinese version were administered to a group $(\mathrm{N}=21)$ of university students who were proficient in both English and Chinese languages. Coefficients of correlation between the English and Chinese versions were significantly high $(\mathrm{r}>.50$, $\mathrm{p}<.05)$. Internal consistency of the SDQ-Chinese was 
examined by calculating the Cronbach alpha values of each subscale. The alpha values of hyperactivity scale (.75), emotional symptoms scale (.78), conduct problems scale (.74), peer problems scale (.70), and prosocial scale (.78) were above or equal to the recommended level of .70 as recommended by Nunnally and Bernstein (1994).

\section{Data Analysis}

Qualitative data obtained from the interview were generalized to examine the participants' intention of participation, their perceived benefits of participation, their attitude towards winning and losing, their reason of adherence to the program and their further expectation of improvement for the program. Quantitative data obtained from their teachers and guardians were examined under the subscales of emotional symptoms, conduct problems, hyperactivity, peer problems, prosocial behavior and the total difficulties score. The scores were compared with the Provisional Banding of SDQ Scores (Goodman, 1997, p.586) suggested by the author.

\section{Results and Discussion}

This study evaluated the impact of a soccer training program on the social and psychological development of the participants. Findings from the interview and questionnaires are provided below.

\section{Demographic Data}

Thirty five participants took part in the study. The mean age was 15.97 years $(S D=1.22)$. They came from 9 different schools with 6 of them in high banding EMI schools (e.g. Ho Lap School, Choi Hung Catholic Secondary School) and the rest 29 from low banding schools in the Wong Tai Sin District.

\section{Findings from Interview with Program Participants}

The interviews were conducted on several Saturday mornings before their practice sessions. In order to make them feel comfortable and able to express freely, they were asked to attend the interview in pairs. Each interview session lasted for about 30 minutes. The interviews aimed at understanding the participants' intention and their perceived benefits of joining the program, their attitude towards winning and losing, their reasons of staying in the program, the reasons why somebody dropped out, and their expectations for further improvement. Findings were summarized as follow.

\section{Intention of participation}

Most participants learned about the soccer training program from their schoolmates or friends. They joined the activity together because they liked to play soccer. By joining the program, they could have more chance to play soccer and they could also gain the identity as a member of a team. The program also offered them the prestige of having a permanent training ground and a fixed time schedule for playing soccer. Some participants also quoted that they joined the program because they wanted to be with their friends. Apparently, most participants joined the program were influenced by their friends, especially by their schoolmates. Very often, they were already teammates in their school teams and they felt more secured if they joined an external activity together.

\section{Perceived benefits of participation}

Participants were able to quote a lot of benefits after joining the program. Among those benefits, social benefits (know more friends) were the most popular. They were able to quote a lot of examples to illustrate that they have known more friends. Some participants claimed that they became more out-spoken and improved their social skills after joining the program. Some participants claimed that they had better control on their temper after joining the program. Fun was also quite frequently quoted as a benefit of joining the program. They were able to describe lots of positive experiences in the previous matches. Health enhancement was seldom quoted as a benefit, but had taken it for granted. One of the participants claimed that he has quitted smoking after joining the program which was in accordance with a previous study (Aaron et al., 1995) indicating the health benefit of participating in exercise program. They were able to acknowledge the social support as a perceived benefit. Many of them claimed that their parents were quite supportive in their participation in this healthy sport activity. They also thought that under this organized sport activity, they were not likely be bullied by gangsters in the district. 


\section{Attitude towards winning and losing}

The program was basically a leisure sport activity and the emphasis was not particularly on winning. Study (Petlichkoff, 1996) also pointed out that in youth sport, winning is frequently a low priority for participation. Yet, in this study, participants still valued winning as an important element. Under winning conditions, the team demonstrated good teamwork and shared support among each other. However, under adverse conditions, all kinds of problems would arise. It was common to attribute defeat to external factors, such as lack of cooperation, over-dependent on individual players, or someone overdominating the whole match. Sometimes this would end in disputes among players or led to isolation of individual players in the team.

\section{Reasons of adherence}

There was a unanimous response that being with friends was the major reason of staying in the team. They generally felt that they have the responsibility of maintaining the team together by actively participating in trainings and matches. They treasured the opportunity of staying together and sharing the same goals, especially, many of them were Form 5 students and would be taking the Hong Kong Certificate of Examination. Some participants also reflected that they received effective coaching provided by the program that helped them to improve their skills. Several participants also claimed that their parents had positive impression towards the program and persuaded them to continue to join the team.

\section{Reasons of attrition}

Since, those took part in the interview were those who stayed in the team, the reasons they gave to explain those who left were merely speculations or their own opinions. They speculated that the reasons of attrition were mainly because of not getting along well with other members, or being challenged by other members of the team. The other reason was that they had limited chance to play in matches. Also, those left might not like the harsh training of the team and gradually lost interest and left.

\section{Expectation for improvement}

Participants were quite eager to make suggestions for the improvement of the program. The interviewer was expecting that requests would be made on increasing materialistic support, however, almost all participants made suggestions on the improvement of group cohesion. They requested stricter discipline control, especially on punctuality during practice sessions. Some hinted that, in some circumstances, undesirable behaviors were not properly dealt with. They expected that the management of the program should handle the team with fairness. Some suggested that more social activities, such as camping, social gatherings, should be held to promote better team spirit. Some felt that there were enough chances for competitions; they preferred more practice sessions rather than competitions. They had the feeling that competitions were quite stressful. The feedback consolidated that the participants were intrinsically motivated in taking part in the program rather than attracted by extrinsic benefits which was in accordance with the Cognitive Evaluation theory (Deci \& Ryan, 1980). Since they participated out of their innate desire and out of their own choice, they had a strong sense of belonging and shared the responsibility in building a good team. They expected a clear and strict team code of conduct that everybody was required to follow. They also expected strong support from the management and their peers.

\section{Findings from Teacher Evaluation by SDQ}

The teachers of the program participants were contacted to evaluate on the behavior of their students by the Strengths and Difficulties Questionnaire (SDQ; Goodman, 1997). Some of the teachers were class teachers of the participants, while some of them were PE teachers of the schools who had a good understanding of the participant. The questionnaires were reduced into 6 scales: Total Difficulties Score (TDS), Emotional Symptoms Score (ESS), Conduct Problem Score (CPS), Hyperactivity Score (HS), Peer Problems Score (PPS), and Prosocial Behavior Score (PBS). The means and standard deviations for different subscales and comparison with the Provisional Banding of SDQ Scores suggested by Goodman (1997) are presented in Table 1. 
Table 1. Teacher Evaluation on the Behavior of Participants by SDQ and Comparison with the Provisional Banding of SDQ Scores.

\begin{tabular}{lllccc}
\hline & Mean & SD & Normal Banding & Borderline Banding & Abnormal Banding \\
\hline TDS & 8.41 & 4.46 & $0-11$ & $12-15$ & $16-40$ \\
ESS & 1.44 & 1.44 & $0-4$ & 5 & $6-10$ \\
CPS & 1.44 & 1.22 & $0-2$ & 3 & $4-10$ \\
HS & 3.19 & 1.91 & $0-5$ & 6 & $7-10$ \\
PPS & 2.34 & 1.47 & $0-3$ & 4 & $5-10$ \\
PBS & 6.50 & 2.02 & $6-10$ & 5 & $0-4$ \\
\hline
\end{tabular}

The mean scores of all the subscales were within the normal banding suggested by Goodman (1997) which was developed by a number of surveys using the SDQ. By further observation, the mean scores of all difficulty indexes except ESS were on the upper end of the suggested normal banding; on the other hand, the strength index (PBS) was on the lower boundary of the suggested normal range. Using the Provisional Banding (Goodman, 1997) as a reference, the sample from this study was, thus, within the normal banding but might envisage occasional difficulties in adapting to society.

Most of the participants in this study were studying in band 3 schools (29 out of 35) in Wong Tai Sin District, which were always considered to have higher chance for the occurrence of behavioral problems. However, the feedback from teachers revealed that this group of students had acceptable behavior in school. Although they did not demonstrate extraordinary prosocial behavior (PBS = 6.50), yet, they did not have too much difficulties in adapting to their school life (TDS $=8.41$ ). In school, they might be quite active (HS = 3.19), sometimes had conduct problems $(\mathrm{CPS}=1.44)$, might have problems with their friends (PPS = 2.34), but emotionally stable (ESS $=1.44)$. Although, comparison with non-participants in this program was not possible due to the absence of data, yet, based on these preliminary descriptive findings, it was reasonable to conclude that participants in this program had demonstrated acceptable behavior in schools.

\section{Findings from Parent Evaluation by SDQ}

The parents of the program participants were contacted through telephone calls upon the consent of the participants. The parents were asked to comment on the behavior of their children at home in the recent 6 months. Their responses were marked according to the items on the SDQ. Similarly, the completed questionnaires were reduced into 6 scales for interpretation. The means and standard deviations for different subscales and comparison with the Provisional Banding of SDQ Scores suggested by Goodman (1997) are presented in Table 2.

Table 2. Parent Evaluation on the Behavior of Participants by SDQ and Comparison with the Provisional Banding of SDQ Scores.

\begin{tabular}{lllccc}
\hline & Mean & $S D$ & Normal Banding & Borderline Banding & Abnormal Banding \\
\hline TDS & 10.95 & 4.56 & $0-13$ & $14-16$ & $17-40$ \\
ESS & 2.40 & 1.73 & $0-3$ & 4 & $5-10$ \\
CPS & 1.85 & 1.63 & $0-2$ & 3 & $4-10$ \\
HS & 3.55 & 2.16 & $0-5$ & 6 & $7-10$ \\
PPS & 3.15 & 1.18 & $0-2$ & 3 & $4-10$ \\
PBS & 6.35 & 1.69 & $6-10$ & 5 & $0-4$ \\
\hline
\end{tabular}


The mean scores of five subscales were within the suggested normal banding with PPS in the borderline banding. The mean scores for difficulty indexes (TDS, ESS, CPS, HS) were again clustered at the upper end of the normal banding, or had exceeded into the borderline banding (PPS), also, the strength index (PBS) was on the lower end. The data from the parents of the participants reviewed that the sample of study were within the normal acceptance of the society but might have encountered problems in getting along with their peers.

The participants in this study were between the ages of 14 and 18 who were undergoing a critical period of adolescent development and faced a set of major life changes. They began to think about themselves and how they relate to others and the broader society (Durkin, 2001). Their parents, sometimes not aware of these changes, would perceive that their children might have some difficulties in getting along with their friends or school life. Especially, when their children expanded their social sphere and had more friends, the parents would worry that their children might be affected by their peers. This discrepancy can explain the relatively high difficulty indexes evaluated by the parents. Yet, during the interview, most players felt that their parents were supportive of their participation in the program. Thus, more communication should be established with the parents so that they could realize the positive development of their children through participating in the program and earn their support.

To conclude, the qualitative data obtained from participants together with the teacher ratings and parental ratings supported the notion that the soccer training program has achieved, through participation in sport activities, the desired impact of developing the participants' own ethnical value and internalize a set of positive values towards society.

\section{Recommendations for Launching Sport Program for Teenagers}

In light of the findings of this investigation, the following recommendations can be made in regard to the promotion, management and development of a sport program for teenagers to foster their moral development.

Most of the participants took part in such program were under the influence of their friends. They preferred to take part in open activities with some companions so they would feel more secured. Thus, recruitment of new members can be more effective if it is made through the invitation of existing members. This will lessen the uncertainties of those who are not familiar with the organization.

Recruitment of new members can also be made through school PE teachers. In the contact with school $\mathrm{PE}$ teachers during this questionnaire collection, they were very supportive and had a positive attitude towards the soccer program. They generally felt that their students benefited from joining the program both in improving their technical skill, as well as in facilitating their moral development and improving their social skill. In fact, many of the program participants were team members in the soccer team of the same schools, their PE teachers were happy that the soccer program could offer their students opportunities to practice for their inter-school competitions.

There have been different reasons given by the program participants for staying with the program. Among them, fun, friends and identity were frequently mentioned. To maintain the attractiveness of such program, all these elements have to be taken into consideration. In this study, several participants demanded that a stricter discipline should be observed, such as punctuality, attendance and obedience to coach. Since a better identity can be developed when affiliating with a well-organized team, hence, to be successful, a positive team image should be developed for such program. Clear and reasonable rules should be formulated under the consultation of all members, and should be strictly implemented. Positive team image can be fostered by wearing tidy team uniform and setting up of unique team culture (e.g. the Brazilian drills) during trainings; especially when they are held in public ground with neighbors of the district around. 
Youth leaders can also be developed from past participants. With their years of participating in the program, they are experienced and fully committed; in fact, they are valuable assets to the program. They can be developed into youth soccer leaders that can assist in the operation of the program. With their enthusiasm and contribution, not only the work of the coach can be shared, they can further exert a positive influence among other young participants.

Relationship with participants' parents also needs to be established. Teenage participants are at the age of change that is related to biological, social, and organizational contexts. The shift from family to peers often leads to confrontation between the child and parents which was a result of lack of communication. From the interviews in this study, information suggested that parents were basically supportive of their children participating in such activities, but had little information on the nature and purpose of the program apart from playing soccer. In recent years, many youth sport activities (e.g. junior age group athletics), always involve the participation of parents, either as spectators, supporters or caretakers. This will allow the parents to be informed of the development of their children and also enable them to have some kind of involvement and, thus, gaining their recognition.

This study suggested that youngsters through participation of the soccer training program were able to expand their social circle, and able to nurture a sense of recognition by affiliating with a group. These are important elements to facilitate successful personal and social development of the individual. In consideration of limited resources implication, such program has been found to be a valuable tool for reducing and preventing behavioral problems and promoting pro-social behavior in both the school as well as the family settings. Further expansion of such program with more resources support is justified.

\section{Direction for further studies}

The current study examined the impact of a soccer training program organized by a social service group on the moral development of their teenage participants. Specific recommendations are made on the launching, administration and development of such program. This study also provides a basis for future investigations and directions.
This study is a cross sectional study and examined the status of the participants at the moment the study was conducted. As noted by Weiss and Petlichkoff (1989), longitudinal research would give us more information on the change of behavior across different phases of sport involvement. Petlichkoff (1996) further suggested that this kind of study can be achieved through the pre- and post-participation assessments of the specific program. It is suggested that further research will be useful if participants are assessed when joining the program and compare the results after staying with the program for several years.

According to information provided by participants during the interview that number of "dropouts" from the program was just a few. However, the reasons for discontinuing in the program have to be considered in order to make improvements to the program. In this study, the reasons of dropping out were only speculated by those staying in the program; the actual reasons have to be confirmed by the dropouts themselves. Further investigation would be required in this area.

This study is a preliminary study and involved a relatively small sample $(\mathrm{N}=35)$, further study with a larger sample, or across districts would be useful in evaluating the effectiveness of similar programs. The results from this study support the development of program such as this one and indicate the need for greater research in these areas.

\section{Acknowledgments}

The author would like to acknowledge the valuable support and assistance of the staff of the Youth Employment Training and Creativity Development Centre at Tsz Wan Shan Zion Children and Youth Integrated Service Centre of Chinese Evangelical Zion Church, and the parents, teachers and participants of the program. 


\section{References}

Aaron, D.J., Dearwater, S.R., Anderson, R.D., Olsen, T., Kriska, A.M., \& Laport, R.E. (1995). Physical activity and the initiation of high-risk health behaviors in adolescents, Medicine and Science in Sports and Exercise, 27, 1639-1645.

Anshel, M.H. (2004). Sources of disordered eating patterns between ballet dancers and non-dancers, Journal of Sport Behavior, 27, 115-133.

Bar-Or, O. (1983). Pediatric sports medicine for the practitioner: From physiologic principles to clinical application. New York: Springer Verlag.

Cheng, C.H.K., Lo, T.W., \& Wong, D.S.W. (2004). Deviant behaviour of adolescents and their psychological correlates in terms of the self and social influence. Journal of Youth Studies, 7(2), 169183.

Core, J., \& Hay, J. (2002). Children's involvement in sport: A developmental perspective. In J.M. Silva, \& D.E. Stevens (Eds.), Psychological foundations of sport (pp. 484-502). Boston, MA: Allyn \& Bacon.

Deci, E.L., \& Ryan, R.M. (1980). The empirical exploration of intrinsic motivation processes. In $\mathrm{L}$. Berkowitz (Ed.), Advances in experimental social psychology, (Vol. 13, pp.39-80), New York: Academic Press.

Durkin, K. (2001). Developmental social psychology: From infancy to old age. Oxford: Blackwell Publications Inc.

Dwyer, T., Sallis, J.F., Blizzard, L., Lazarus, R., \& Dean, K. (2001). Relation of academic performance to physical activity and fitness in children. Pediatric Exercise Science, 13, 225-238.

Eccles, J.S., \& Barber, B.L. (1999). Student council, volunteering, basketball, or marching band: What kind of extracurricular involvement matters? Journal of Adolescent Research, 14(1), 10-43.
Fraser-Thomas, J.L., Cote, J., \& Deakin, J. (2005). Youth sport programs: An avenue to foster positive youth development. Physical Education and Sport Pedagogy, 10(1), 19-40.

Gardner, R.E., \& Janelle, C.M. (2002). Legitimacy judgments of perceived aggression and assertion by contact and non-contact sport participants. International Journal of Sport Psychology, 33, 290306.

Gilman, R. (2001). The relationship between life satisfaction, social interest, and frequency of extracurricular activities among adolescent students. Journal of Youth and Adolescence, 20, 749-767.

Goodman, R. (1997). The strength and difficulties questionnaire: A research note. Journal of Child Psychology and Psychiatry, 38(5), 581-586.

Hansen, D.M., Larson, R.W., \& Dworkin, J.B. (2003). What adolescents learn in organized youth activities: A survey of self-reported developmental experiences. Journal of Research on Adolescence, 13(1), 25-55.

Hollander, D.B., Meyers, M.C., \& Arnold, L. (1995). Psychological factors associated with over-training: implications for youth sport coaches, Journal of Sport Behavior, 18(1), 3-17.

Larson, R.W. (2000). Toward a psychology of positive youth development. American Psychologist, 55, 170183.

Lindner, K.J. (1999). Sport participation and perceived academic performance of school children and youth. Pediatric Exercise Science, 11(2), 129-143.

Nunnally, J.C., \& Bernstein, I.H. (1994). Psychometric Theory. New York: McGraw-Hill.

Petlichkoff, L.M. (1996). The drop out dilemma in sport. In O. Bar-Or (Ed.), Encyclopaedia of sports medicine: The child and adolescent athlete (Vol. 6, pp. 418-430). Oxford, England: Blackwell Scientific. 
Scalan, T.K., Carpenter, P., Schmidt, G., Simons, J., \& Keeler, B. (1993). An introduction to the sport commitment model. Journal of Sport and Exercise Psychology, 15, 1-15.

Security Bureau. (2006). Juveniles and young persons arrested for crime, 1997 to 2006. Retrieved from http://www.sb.gov.hk/eng/pub/fcc/FCC_Report_26.pdf

Shields, D.L.L., \& Bredemeier, B.L. (1995). Character development and physical activity. Champaign, IL: Human Kinetics.

Wankel, L.M., \& Kreisel, P.S. (1985). Factors underlying enjoyment of youth sports: Sport and age group comparisons. Journal of Sport Psychology, 7, 51-64.
Weiss, M.R., \& Petlichkoff, L.M. (1989). Children's motivation for participation in and withdrawal from sport: Identifying the missing links. Pediatric Exercise Science, 1, 195-211.

\section{Correspondence:}

\section{Eric C.K. TSANG}

Department of Creative Arts and Physical Education (PE Division)

The Hong Kong Institute of Education,

Tai Po, New erritories,

Hong Kong.

Tel: (852) 29487861

E-mail: cktsang@ied.edu.hk 